\title{
An aerosol spray alternative to cigarette smoking in the study of the behavioral and physiological effects of nicotine
}

\author{
KENNETH A. PERKINS, LEONARD H. EPSTEIN, RICHARD STLLLER, \\ J. RICHARD JENNINGS, CURT CHRISTIANSEN, and TERRY MCCARTHY \\ Western Psychiatric Institute \& Clinic, University of Pittsburgh School of Medicine, Pittsburgh, Pennsylvania
}

\begin{abstract}
For studies of the behavioral and physiological effects of nicotine in smokers, delivery of nicotine via cigarette smoking is highly variable and difficult to control. A more precise method of delivery is needed in order to accurately manipulate the amount of nicotine being presented and, thus, to determine its quantitative effects. The objective of the study reported here was to test an aerosol nasal-spray method of delivering measured doses of nicotine. Eleven healthy males were presented $0 \mathrm{mg}$ (placebo), $0.5 \mathrm{mg}, 1.0 \mathrm{mg}$, and $2.0 \mathrm{mg}$ of nicotine over 5 min during four separate sessions, and changes were observed in plasma nicotine concentration and cardiovascular activity. Dose-response relationships were observed between nicotine presented via this method and plasma nicotine, heart rate, systolic blood pressure, and, to a lesser extent, diastolic blood pressure. These results suggest that this aerosol spray method of presenting nicotine provides the measured doses necessary for quantification of nicotine's effects.
\end{abstract}

Nicotine is believed to be the primary component of tobacco that is responsible for many of the widespread acute effects of smoking, including changes in cardiovascular activity (Koch et al., 1980; Rosenberg, Benowitz, Jacob, \& Wilson, 1980; Spohr et al., 1979; Suter, Buzzi, \& Battig, 1983), attention and task performance (Wesnes \& Warburton, 1983), affect (Epstein, Dickson, McKenzie, \& Russell, 1984; Pomerleau, Turk, \& Fertig, 1984), and a variety of sympathetic and metabolic parameters (Aceto \& Martin, 1982; Cryer, Haymond, Santiago, \& Shah, 1976; Spohr et al., 1979). Craving and withdrawal effects following smoking cessation are also thought to be largely due to the absence of nicotine (Hughes et al., 1984; Jaffe \& Kanzler, 1979), and smokers will not continually smoke nontobacco cigarettes (Mangan \& Golding, 1984). Thus, the effects of nicotine appear to be critical in the maintenance of smoking behavior.

Despite this knowledge of nicotine's qualitative effects, determination of nicotine's specific quantitative effects is difficult due to numerous methodological problems inherent in nicotine research involving tobacco smoking. First, smoking does not allow for the isolation of the effects due to nicotine since tobacco contains over 4,000 compounds in addition to nicotine (Dube \& Green, 1982). More importantly, precisely measured doses of nicotine, which are essential to determine its quantitative effects, are difficult to provide via cigarettes. Use of cigarettes with a single specified nicotine content may lead to changes in smok-

This research was supported by NIMH Clinical Research Center Grant No. MH-30915 and by NHLBI Grant No. HL07560. The authors express their sincere appreciation to John Foglia, Marc Auerbach, and Kim Smith for their assistance in completing this study. Please send reprint requests to: Kenneth A. Perkins, Western Psychiatric Institute \& Clinic, 3811 O'Hara St., Pittsburgh, PA 15213. ing topography and, therefore, nicotine intake, depending on whether the nicotine content in the brand preferred by subjects is more or less than that contained in the experimental cigarettes (Epstein, Ossip, Coleman, Hughes, \& Wiist, 1981; Gust \& Pickens, 1982; Herning, Jones, Bachman, \& Mines, 1981; Suter, Buzzi, \& Battig, 1983; Wesnes \& Warburton, 1983). The coaching of puff frequency, a procedure employed in many studies, allows for variations in other aspects of topography, such as puff volume and depth of inhalation, which have been shown to vary depending on characteristics of the ongoing experimental situation (Comer \& Creighton, 1978; Mangan \& Golding, 1978; Rose, Ananda, \& Jarvik, 1983; Suter, Buzzi, Woodson, \& Battig, 1983). Methods of measuring amount of smoke intake during cigarette smoking (e.g., Gust, Pickens, \& Pechacek, 1983; Jenkins \& Gayle, 1984) and for providing specific amounts of cigarette smoke (Rose, Tashkin, Ertle, Zinser, \& Lafer, 1985) have been devised, but these methods do not provide for specific assessment of nicotine intake.

Available alternative methods of delivering nicotine are not satisfactory for use in research on the quantitative behavioral and physiological effects of nicotine. Any form of tobacco prevents the isolation of the effects due to nicotine, and most nontobacco methods (e.g., nicotine gum chewing, intravenous nicotine administration) do not allow for the rapid uptake of nicotine via inhalation, which is the manner characteristic of cigarette smoking and which is considered crucial to obtaining the reinforcing effects of nicotine (Russell \& Feyerabend, 1978). We felt that an aerosol spray method could potentially solve these methodological problems, since a fixed concentration of nicotine may be prepared in solution and then inhaled nasally via aerosol spray. Nasal inhalation of nicotine, such as that which 
occurs with snuff, has been found to produce plasma nicotine levels nearly as high and almost as quickly as inhalation during cigarette smoking (Russell, Jarvis, Devitt, \& Feyerabend, 1981). In addition, an aerosol method potentially allows for double-blind presentation of nicotine, whereas the typical procedure of "sham-smoking," used as a control for smoking, cannot.

The objective of the present study was to test an aerosol nasal-spray method of delivering measured doses of nicotine. Dose-response effects of nicotine on plasma nicotine, heart rate, and systolic and diastolic blood pressure were used as indices of the effectiveness of the differential dosing procedure. Based on the results of previous research that employed other means to deliver nicotine (e.g., Benowitz, Jacob, Jones, \& Rosenberg, 1982; Henningfield, Miyasato, \& Jasinski, 1985; Spohr et al., 1979), we hypothesized that plasma nicotine concentration would be linearly related to nicotine dose, whereas cardiovascular increases would be dosedependent but nonlinear.

\section{METHOD}

\section{Subjects}

Subjects were 11 healthy males, aged 18-22 years (mean $=19.3$ years), who had smoked $20-40$ cigarettes per day (mean $=25.9 \pm 6.3$ cigarettes) for at least 6 months (mean $=23.7 \pm 15.9$ months). Subjects denied taking regular medication and denied any significant health problems. Subjects were paid $\$ 40$ for their participation.

\section{Study Design}

A completely repeated within-subjects design was used to control for random variations in subject characteristics, such as body weight and smoking history, that may influence the effects of nicotine. Four nicotine doses were presented during four separate sessions on different mornings. All sessions were conducted between 9:00 a.m. and 12:00 noon. Subjects were instructed to abstain from tobacco, caffeine, and food from midnight the previous night until each of their morning sessions to eliminate the effects of each substance on observed cardiovascular changes and on absorption of nicotine (Feyerabend \& Russell, 1978).

\section{Nicotine Solution}

The four nicotine doses were $0 \mathrm{mg}$ (placebo), $0.5 \mathrm{mg}$, $1.0 \mathrm{mg}$, and $2.0 \mathrm{mg}$. The order of presentation of the doses was counterbalanced across subjects. Each dose consisted of $1.8 \mathrm{ml}$ of $0.9 \%$ sodium chloride solution, together with the $0,0.5,1.0$, or $2.0 \mathrm{mg}$ of $\mathrm{L}$-nicotine and $10 \mathrm{mg}$ of anise oil, which was used to mask the taste and smell of nicotine. These ingredients were mixed by sonification and passed through a $0.22-\mu \mathrm{m}$ Milex G-S filter into a sterile nasal-spray aerosol pump bottle delivering a measured amount $(0.18 \mathrm{ml}$, confirmed by repeat assessment in our lab) of solution with each spray. The solu- tion was sterile and nonpyrogenic, and it was buffered to a $\mathrm{pH}$ of 6.1 .

\section{Procedure}

At the beginning of each session, silver/silver chloride electrodes were placed on the right shoulder, the left rib cage, and the left shoulder (for ground) for measurement of heart rate. A manually inflated blood pressure cuff was placed on the upper nonpreferred arm. In addition, for 3 randomly chosen subjects, an indwelling butterfly cannula perfused with heparin was inserted into the cubital vein of the forearm to provide intermittent blood samples.

Subjects sat in a comfortable armchair (at a $45^{\circ}$ angle) within a sound-proofed, climate-controlled experiment room. The cardiovascular monitoring equipment was connected to a Grass polygraph in an adjoining laboratory by electrical connections in a wall interface. A one-way window between the experiment room and laboratory allowed for monitoring of the sessions from the laboratory. Subjects were instructed to remain quiet for at least $5 \mathrm{~min}$ to become habituated to the surroundings and monitoring equipment. Next, they rested for an additional $5 \mathrm{~min}$ while listening to soft music (baseline period).

The nicotine solution was presented in a double-blind fashion via the nasal-spray pump. Administration of the solutions occurred over five presentations separated by 1 min of quiet rest. Each of the presentations contained one fifth of the total dose and consisted of one spray to each nostril in quick succession (approximately 5-10 sec apart). One minute after the fifth (last) presentation ( $5 \mathrm{~min}$ after the first), subjects again listened to soft music while resting quietly for a period of $25 \mathrm{~min}$.

Heart rate (HR), systolic blood pressure (SBP), and diastolic blood pressure (DBP) were obtained during the last minute of baseline, immediately after the last presentation (post- 0 ), and 5, 10, 15, 20, and $25 \mathrm{~min}$ after the last presentation (postdrug period). Approximately $5 \mathrm{ml}$ of blood was obtained from 3 subjects after each blood pressure measurement.

Finally, after presentation of the first placebo or nicotine dose, the presence or absence of symptoms related to nicotine intake was noted by a trained observer using a simple behavioral rating scale. Symptoms on this scale included sneezing, tearing, coughing, and sniffling, and interrater agreements ranged from $94 \%$ (sniffling) to $100 \%$ (sneezing). These ratings were obtained to determine whether the doses could be distinguished on the basis of observable behavioral responses. Because the number of symptoms diminished after the first presentation of solution, analyses were based on those symptoms that occurred following the first presentation (i.e., peak number of symptoms).

\section{Cardiovascular and Plasma \\ Nicotine Measures}

HR was determined by counting R-waves from one channel of the polygraph displaying the EKG trace. The 
blood pressure cuff was attached to a standard Grass sphygmomanometer EKG-pulse preamplifier, and cuff pressure was displayed on a second channel of the polygraph while a third, adjacent channel displayed Korotkoff sounds detected by a microphone in the cuff. SBP was determined to be the pressure of the cuff at the first Korotkoff sound, and DBP was determined to be the cuff pressure at the last Korotkoff sound.

Each blood sample was collected into a 7-ml Vacutainer ${ }^{\circledR}$ (EDTA) tube, which was kept approximately $5^{\circ} \mathrm{C}$ until the end of the experimental session (less than $40 \mathrm{~min}$ ). Then, each sample was mixed and centrifuged at $5^{\circ} \mathrm{C}$.
The plasma was separated and placed into polypropylene vials and stored at $-60^{\circ} \mathrm{C}$. The analytical determination of plasma nicotine level first involved separating the nicotine from the plasma by a column extraction method using a 3-ml silica gel and a 3-ml octyl $\left(\mathrm{C}_{8}\right)$ column "piggybacked" with a column adapter. The eluates were concentrated to dryness with a Savant concentrator under vacuum (Savant, Farmingdale, NY). Added to the nicotine residue was $50 \mu \mathrm{l}$ of toluene:ethanol (1:1), and $1 \mu \mathrm{l}$ was injected in a nitrogen-selective equipped gas chromatograph (Varian, Walnut Creek, CA) with a 20-M carbowax ultrabond column (Ultra Scientific, New Hope,

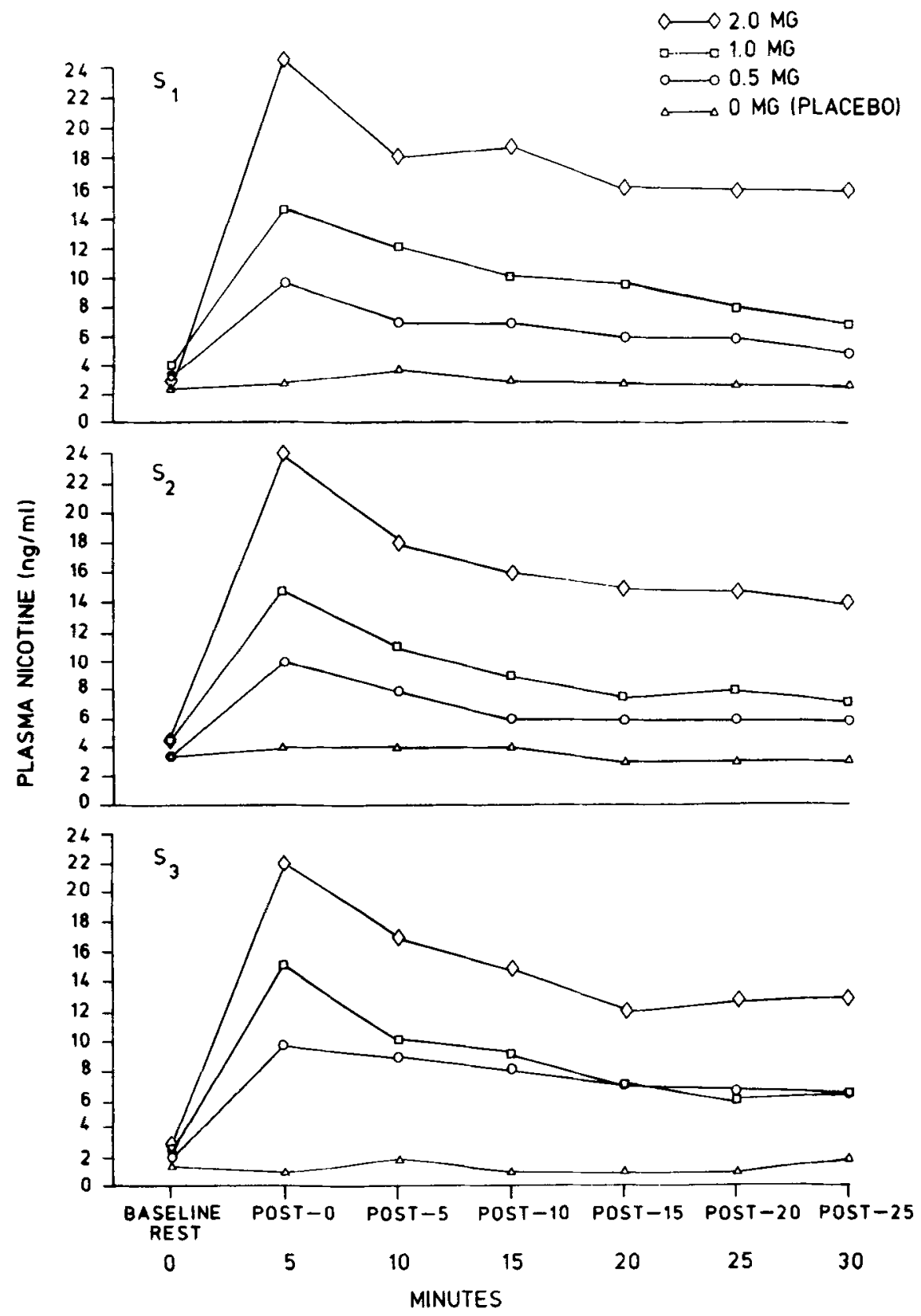

Figure 1. Plasma nicotine of 3 subjects during baseline and postdrug periods following $\mathbf{0} \mathrm{mg}$ (placebo), $0.5 \mathrm{mg}, 1.0 \mathrm{mg}$, and $2.0 \mathrm{mg}$ of nicotine. 
Table 1

Summary of Analyses of Covariance for Heart Rate, Systolic Blood Pressure, and Diastolic Blood Pressure

\begin{tabular}{lcrrr} 
& & \multicolumn{3}{c}{$F$ ratios* } \\
\cline { 4 - 5 } \multicolumn{1}{c}{ Effect } & $d f$ & HR & SBP & DBP \\
\hline Nicotine Dose & 3,29 & 23.24 & 6.23 & 10.17 \\
Period & 6,60 & 36.30 & 11.30 & 10.78 \\
Dose $\times$ Period & 18,180 & 7.83 & 2.29 & 2.77 \\
\hline
\end{tabular}

*All ps < .005.

MA). The assay was sensitive and accurate to plasma concentrations of less than $0.5 \mathrm{ng} / \mathrm{ml}$. Each determination was made blind to the particular dose presented during each session and was performed on a minimum of three extracted assays, with the mean of those assays used as the determination ( $S D=4.2 \%$ ). The assay inter- and intraday reliabilities were $3.6 \%$ and $4.1 \%$, respectively. This assay was modified from that of Hengen and Hengen (1978).

\section{Statistical Analyses}

Analyses of variance (ANOVAs) were used to determine any differences in baseline cardiovascular measures across sessions and conditions. The cardiovascular measures collected subsequent to the baseline period were subjected to a completely repeated within-subjects overall analysis of covariance (ANCOVA), using baseline values as the covariate, with dose (four levels) and period (seven levels), as the factors. Pairwise comparisons were performed using Fisher's protected least significant difference (LSD) procedure (level of $p<.01$ ) to determine the differences in cardiovascular changes between pairs of consecutive doses (i.e., 0 vs. $0.5 \mathrm{mg}, 0.5 \mathrm{vs} .1 .0 \mathrm{mg}$, and 1.0 vs. $2.0 \mathrm{mg}$ ) at each period. In addition, an ANOVA was performed on the number of symptoms present following the first presentation of nicotine or placebo. Pairwise comparisons were then performed between pairs of consecutive doses.

\section{RESULTS}

ANOVAs of baseline values for each measure across Sessions 1-4 and across the four nicotine dose conditions confirmed that there were no significant differences in initial baseline levels prior to particular sessions or conditions.

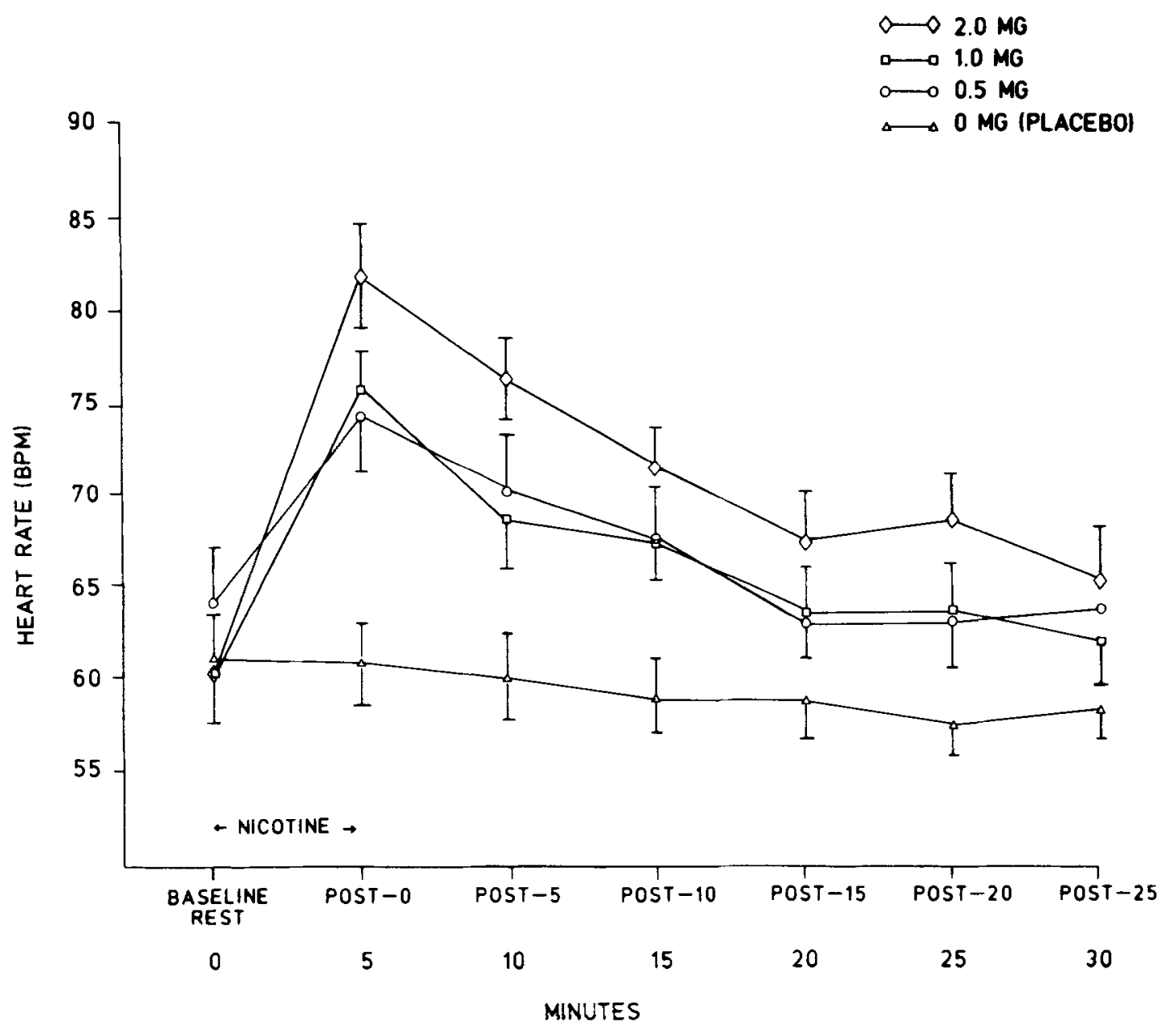

Figure 2. Mean ( \pm SEM) heart rate during baseline and postdrug periods following $0 \mathrm{mg}$ (placebo), $0.5 \mathrm{mg}, 1.0 \mathrm{mg}$, and $2.0 \mathrm{mg}$ of nicotine. 
As presented in Figure 1, plasma nicotine levels for the 3 subjects from whom blood samples were obtained showed a very clear linear, dose-dependent relationship with nicotine. The peak value for each dose was very similar across subjects.

The means and standard errors for HRs, SBPs, and DBPs during baseline and the six postdrug periods are displayed in Figures 2-4. The summary of results of the overall ANCOVAs for each measure is displayed in Table 1 . The main effects of nicotine dose, measurement period, and the interaction of dose $\times$ period were consistently significant across cardiovascular measures.

Pairwise comparisons for the data shown in Figure 2 $(p<.01)$ determined that the 0.5 -mg dose produced significantly greater $\mathrm{HR}$ compared with the placebo $(0 \mathrm{mg})$ at 0,5 , and 10 min postdrug. None of the HR differences between $0.5 \mathrm{mg}$ and $1.0 \mathrm{mg}$ was significant. The $2.0-\mathrm{mg}$ dose produced greater $H R$ than did the $1.0 \mathrm{mg}$ at 0 and $5 \mathrm{~min}$ postdrug. The $0.5-\mathrm{mg}$ dose produced greater SBP than did the placebo at the first minute of the postdrug period, as shown in Figure 3, but higher doses of nicotine produced no additional effects of SBP increase beyond that due to $0.5 \mathrm{mg}$. As demonstrated in Figure 4, the 0.5-mg dose produced greater DBP than did the placebo at 0,10 , and $20 \mathrm{~min}$ postdrug, but none of the differences between $0.5 \mathrm{mg}$ and $1.0 \mathrm{mg}$ was significant. The 2.0-mg dose produced greater DBP than did $1.0 \mathrm{mg}$ at 0,5 , and 25 min postdrug.

Finally, ANOVA of behavioral ratings showed a significant effect of nicotine dose $[F(3,40)=7.21, p<$ $.001]$. The results were similar to the cardiovascular results: pairwise comparisons showed that $0.5 \mathrm{mg}$ produced marginally more symptoms than did the placebo and that $2.0 \mathrm{mg}$ produced marginally more symptoms than did $1.0 \mathrm{mg}$. The difference between symptoms caused by $1.0 \mathrm{mg}$ and $0.5 \mathrm{mg}$ was not significant. A greater number of symptoms was observed in 5 of the 11 subjects following $0.5 \mathrm{mg}$ compared with the placebo, in 5 of the 11 following $1.0 \mathrm{mg}$ compared with $0.5 \mathrm{mg}$, and in 4 of the 11 following $2.0 \mathrm{mg}$ compared with $1.0 \mathrm{mg}$.

\section{DISCUSSION}

The results demonstrate that this aerosol method allows for precise presentation of nicotine doses in a manner similar to that in which nicotine is inhaled during cigarette

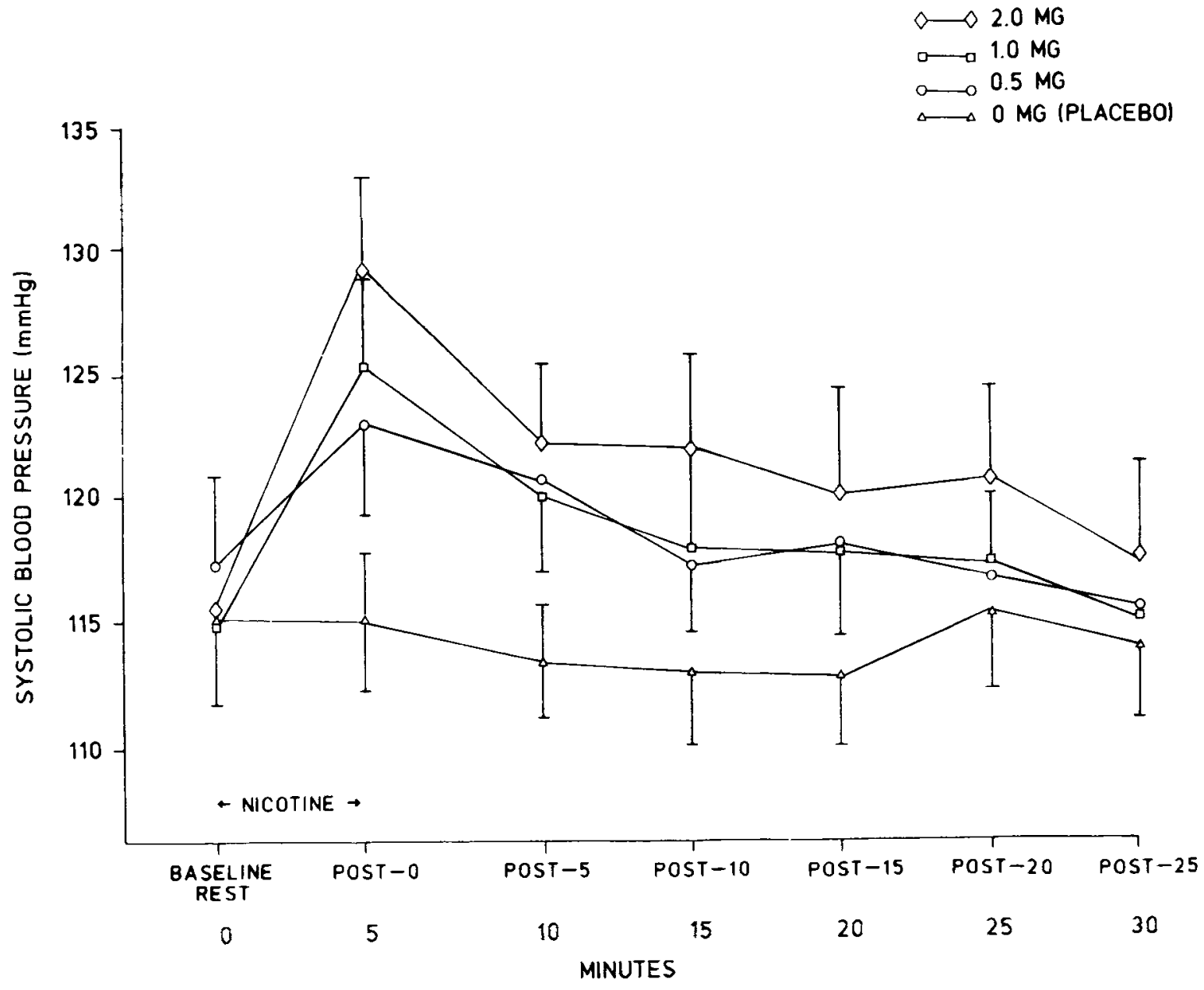

Figure 3. Mean ( \pm SEM) systolic blood pressure during baseline and postdrug periods following $0 \mathrm{mg}$ (placebo), $0.5 \mathrm{mg}$, $1.0 \mathrm{mg}$, and $2.0 \mathrm{mg}$ of nicotine. 


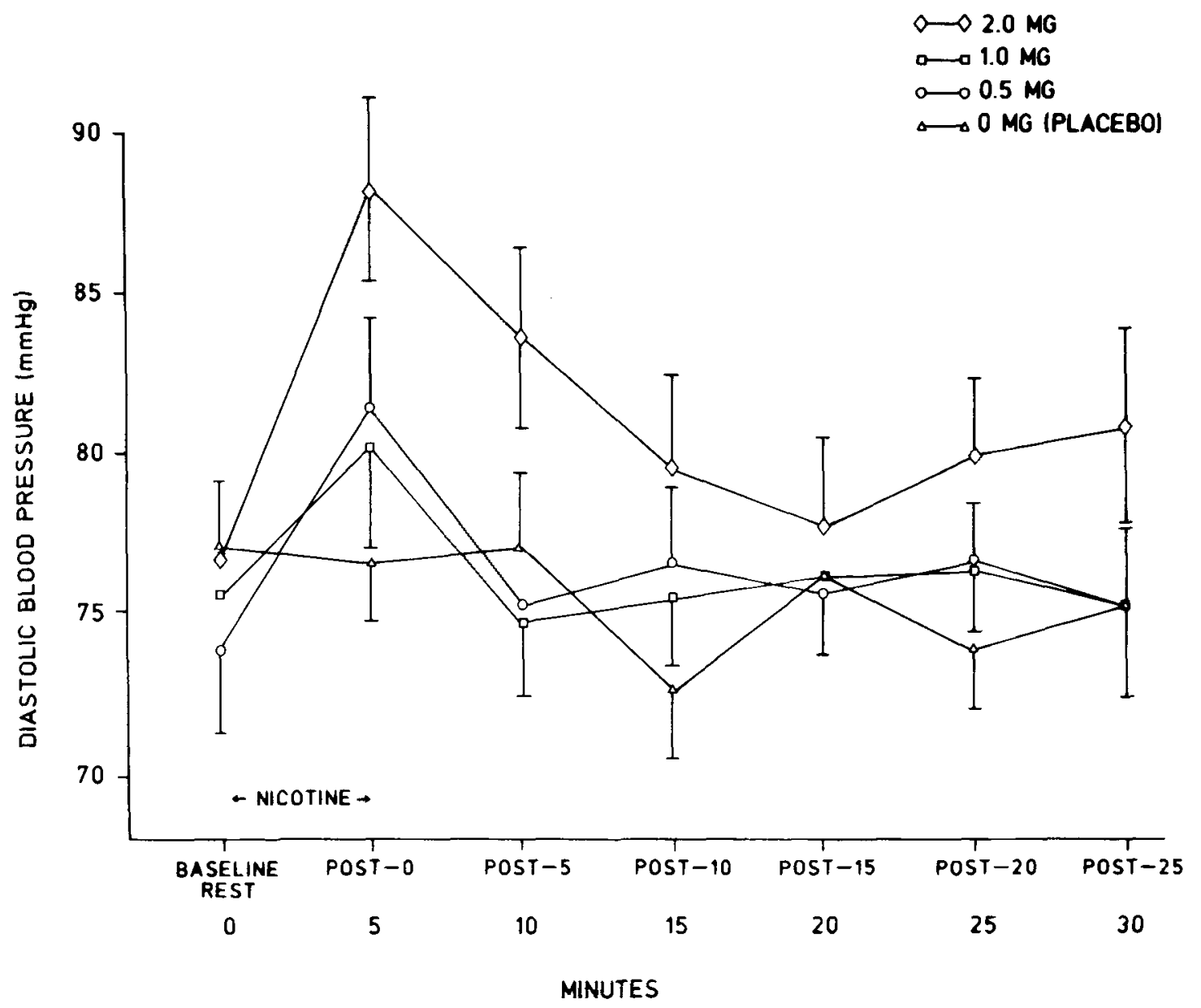

Figure 4. Mean ( \pm SEM) diastolic blood pressure during baseline and pestdrug periods following $0 \mathrm{mg}$ (placebo), $0.5 \mathrm{mg}$, $1.0 \mathrm{mg}$, and $2.0 \mathrm{mg}$ of nicotine.

smoking. Dose-dependent increases from resting baseline to the first minute postdrug (peak) were found for plasma nicotine $(0,+6.7,+11.1$, and $+20.3 \mathrm{ng} / \mathrm{ml}$ for $0,0.5$, 1.0 , and $2.0 \mathrm{mg}$ nicotine, respectively), heart rate $(-0.6$, $+10.2,+15.0$, and $+21.5 \mathrm{BPM})$, systolic blood pressure $(-0.1,+5.2,+10.2$, and $+13.7 \mathrm{~mm} \mathrm{Hg})$, and, to a lesser extent, diastolic blood pressure $(-0.4,+7.4,+4.3$, and $+11.4 \mathrm{~mm} \mathrm{Hg}$ ). The peak plasma nicotine levels for these doses were very similar to those obtained by other researchers employing cigarettes with comparable nicotine content (McNabb, Ebert, \& McCusker, 1982; Russell et al., 1983). Furthermore, these peak levels occurred immediately after the last presentation of nicotine (approximately 5-6 min after the first presentation), as numerous other researchers have found by delivering nicotine via cigarettes (Feyerabend \& Russell, 1978; McNabb et al., 1982). However, important advantages of this aerosol spray method are the nearly linear relationship between dose and plasma nicotine increase and the consistency of the plasma levels at each dose across subjects. Research with cigarettes has demonstrated widely varying peak plasma nicotine levels between subjects smoking identical cigarettes (Armitage et al., 1975; Herning, Jones,
Bachman, \& Mines, 1983), as well as similar peak plasma levels within subjects after smoking high- versus lownicotine cigarettes (Feyerabend, Ings, \& Russell, 1985). For example, Herning et al. (1983) found that only $25 \%$ of the variability in plasma nicotine levels was due to the cigarette's nicotine yield, whereas a majority of the variability was due to identified individual differences in smoking behavior. Similarly, Feyerabend et al. (1985) found that, despite providing subjects with cigarettes differing four-fold in nicotine content $(2.4 \mathrm{mg}$ vs. $0.6 \mathrm{mg}$ ), peak plasma nicotine differed by very little (approximately $32 \mathrm{ng} / \mathrm{ml}$ vs. $25 \mathrm{ng} / \mathrm{ml}$ ). In the present study, by contrast, peak levels for Subjects 1, 2, and 3 were 24.7 , 24.0 , and $22.0 \mathrm{ng} / \mathrm{ml}$, respectively, following the $2.0-\mathrm{mg}$ dose, and $9.5,10.0$, and $9.7 \mathrm{ng} / \mathrm{ml}$ following the $0.5-\mathrm{mg}$ dose.

Cardiovascular increases following $0.5 \mathrm{mg}$ of nicotine were significantly greater than those following the placebo, but few of the increases due to $1.0 \mathrm{mg}$ were significantly greater than those due to $0.5 \mathrm{mg}$. This observation generally confirms that the relationship between nicotine and cardiovascular activity is nonlinear. For example, the $0.5-\mathrm{mg}$ dose increased HR an average of 
10.2 beats per minute (BPM) from baseline to the first minute of the postdrug period. However, twice that amount of nicotine $(1.0 \mathrm{mg})$ resulted in an HR increase only 4.8 BPM greater, and a dose four times that amount $(2.0 \mathrm{mg}$ ) produced an HR increase only $11.3 \mathrm{BPM}$ greater than that due to $0.5 \mathrm{mg}$.

One drawback of this procedure is the inability to completely mask the effects of nicotine with the oil of anise. Slightly greater symptoms were observed in higher doses compared with the next lower dose, although this was true for less than half of the individual subjects. Additional work is needed to devise stronger and/or different masking agents that might better hide the observable as well as subjective effects of nicotine solution.

Some smoking researchers are interested in studying the effects of various manipulations on smoking behavior, as well as the more general effects of smoking, and, thus, would have greater need for devices measuring smoking topography. However, other researchers are more interested in examining the important, specific behavioral and physiological effects of nicotine noted earlier in the introduction. The aerosol spray methodology described here may enable these latter researchers to isolate and assess the quantitative effects of nicotine more accurately than has previously been possible using cigarette smoking.

\section{REFERENCES}

ACETo, M. D., \& MARTIN, B. R. (1982). Central actions of nicotine. Medicinal Research Reviews, 2, 43-62.

Armitage, A. K., Dollery, C. T., George, C. F., Houseman, T. H., LEWIS, P. J., \& TuRner, D. M. (1975). Absorption and metabolism of nicotine from cigarettes. British Medical Journal, 4, 313-316.

Benowitz, N. L., JACOB, P., Jones, R. T., \& ROSEnberG, J. (1982). Interindividual variability in the metabolism and cardiovascular effects of nicotine in man. Journal of Pharmacology \& Experimental Therapeutics, 221, 368-372.

Comer, A. K., \& Creighton, D. E. (1978). The effect of experimental conditions on smoking behaviour. In R. E. Thomton (Ed.), Smoking behaviour: physiological and psychological influences (pp. 76-86). Edinburgh: Churchill Livingstone.

Cryer, P. E., Haymond, M. W., Santiago, J. V., \& Shah, S. D. (1976). Norepinephrine and epinephrine release and adrenergic mediation of smoking associated hemodynamic and metabolic events. New England Journal of Medicine, 295, 573-577.

DUBE, M., GREEN, C. R. (1982). Methods of collection of smoke for analytical purposes, Recent Advances in Tobacco Science, $\mathbf{8}$ 42-102.

Epstein, L. H., Dickson, B. E., McKenzie, S., \& Russell, P. O (1984). The effect of smoking on perception of muscle tension. Psy chopharmacology, 83, 107-113.

Epstein, L. H., Ossip, D. J., Coleman, D., Hughes, J., \& WiIst, W (1981). Measurement of smoking topography during withdrawal or deprivation. Behavior Therapy, 12, 507-519.

Feyerabend, C., INGS, R. M. J., RuSSEll, M. A. H. (1985). Nicotine pharmacokinetics and its application to intake from smoking, British Joumal of Clinical Pharmacology, 19, 239-247.

Feyerabend, C., \& Russell, M. A. H. (1978). Effect of urinary pH and nicotine excretion rate on plasma nicotine during cigarette smoking and chewing nicotine gum. British Journal of Phamacology, 5 , 293-297.

GUST, S. W., \& Prckens, R. W. (1982). Does cigarette nicotine yield affect puff volume? Clinical Pharmacology \& Therapeutics, 32, 418-422.

Gust, S. W., Pickens, R. W., se Pechacex, T. F. (1983). Recording puff volume in smoking. Behavior Research Methods \& Instrumentation, 15, 341-343.
Hengen, N., HENGEN, M. (1978). Gas-liquid chromatographic determination of nicotine and cotinine in plasma. Clinical Chemistry, 24, $50-53$.

Henningfield, J. E., Miyasato, K. \&asinski, D. R. (1985). Abuse liability and pharmacodynamic characteristics of intravenous and inhaled nicotine. Journal of Pharmacology \& Experimental Therapeutics, 234, 1-12.

Herning, R. I., Jones, R. T., Bachman, J., \& Mines, A. H. (1981). Puff volume increases when smoking low nicotine cigarettes. British Medical Journal, 283, 181-189.

HeRning, R. I., Jones, R. T., Bachiman, J., \& Mines, A. H. (1983). How a cigarette is smoked determines blood nicotine levels. Clinical Pharmacology \& Therapeutics, 33, 84-90.

Hughes, J. R., Hatsukami, D. K., Pickens, R. W., Krahn, D., MaLIN, S., \& LUKNIC, A. (1984). Effect of nicotine on the tobacco withdrawal syndrome. Psychopharmacology, 83, 82-87.

JAFFe, J. H., \& KANZLER, M. (1979). Smoking as an addictive disorder. In N. A. Krasnegor (Ed.), Cigarette smoking as a dependence process (pp. 4-23). Washington, DC: U.S. Government Printing Office.

JENKINS, R. A., \& GAYLE, T. M. (1984). An instrumental cigarette smoking monitor designed for the direct measurement of smoke particulate matter generated in human smoking studies. Behavior Research Methods, Instruments, \& Computers, 16, 263-267.

Koch, A., hoffmann, K., Steck, W., Horsch, A., Hengen, N., Morl, H., Harenberg, J., Spohr, U., \& Weber, E. (1980). Acute cardiovascular reactions after cigarette smoking. Atherosclerosis, 35, 67-75.

Mangan, G. L., \& Golding, J. (1978). An 'enhancement' model of smoking maintenance? In R. E. Thornton (Ed.), Smoking behaviour: physiological and psychological influences (pp. 87-114). Edinburgh: Churchill Livingstone.

Mangan, G. L., \& Gol.ding, J. (1984). The psychopharmacology of smoking. Cambridge: Cambridge University Press.

MCNABb, M. E., Ebert, R. V., \& MCCUSKER, K. (1982). Plasma nicotine levels produced by chewing nicotine gum. Journal of the American Medical Association, 248, 865-868.

Pomerleau, O. F., Turk, D. C., Fertig, J. B. (1984). The effects of cigarette smoking on pain and anxiety. Addictive Behaviors, 9, 265-271.

Rose, J. E., ANANDA, S., \& Jarvik, M. E. (1983). Cigarette smoking during anxiety-provoking and monotonous tasks. Addictive Behaviors, 8, 353-359.

Rose, J. E., Tashkin, D. P., Ertle, A., Zinser, M. C., \& Lafer, R. (1985). Sensory blockade of smoking satisfaction. Pharmacology, Biochemistry, \& Behavior, 23, 289-293.

Rosenberg, J., Benowitz, N. L., Jacob, P., Wilson, K. M. (1980). Disposition kinetics and effects of intravenous nicotine. Clinical Pharmacology \& Therapeutics, 28, 517-522.

Russell, M. A. H., \& Feyerabend, C. (1978). Cigarette smoking: a dependence on high-nicotine boli. Drug Metabolism Reviews, 8, 29-57.

Russell, M. A. H., Jarvis, M. J., Devitt, G., \& Feyerabend, C. (1981). Nicotine intake by snuff users. British Medical Journal, 283, 814-817.

Spohr, U., Hofmann, K., Steck, W., Harenberg, J., Walter, E., Hengen, N., Augustin, J., Morl, H., Кoch, A., Horsch, A., \& WEBER, E. (1979). Evaluation of smoking-induced effects on sympathetic, hemodynamic, and metabolic variables with respect to plasma nicotine and $\mathrm{COHb}$ levels. Atherosclerosis, 33, 271-283.

Suter, T. W., Buzzi, R, \& Battig, K. (1983). Cardiovascular effects of smoking cigarettes with different nicotine deliveries. Psychopharmacology, 80, 106-112.

Suter, T. W., Buzzi, R., Woodson, P. P., \& Battig, K. (1983). Psychophysiological correlates of conflict solving and cigarette smoking. Activitas Nervosa Superior, 25, 261-272.

Wesnes, K., \& WARBurton, D. M. (1983). Smoking, nicotine, and human performance. Pharmacology \& Therapeutics, 21, 189-208.

(Manuscript received May 14, 1986; revision accepted for publication July 17,1986 .) 